\title{
Feedback-Induced Temporal Control of "Breathing" Polymersomes To Create Self-Adaptive Nanoreactors
}

\author{
Hailong Che, Shoupeng Cao, and Jan C. M. van Hest*(i) \\ Bio-organic Chemistry, Eindhoven University of Technology, P.O. Box 513 (STO 3.41), 5600MB Eindhoven, The Netherlands
}

\section{Supporting Information}

ABSTRACT: Here we present the development of selfregulated "breathing" polymersome nanoreactors that show temporally programmable biocatalysis induced by a chemical fuel. $\mathrm{pH}$-sensitive polymersomes loaded with horseradish peroxidase (HRP) and urease were developed. Addition of an acidic urea solution ("fuel") endowed the polymersomes with a transient size increase and permeability enhancement, driving a temporal "ON" state of the HRP enzymatic catalysis; subsequent depletion of fuel led to shrinking of the polymersomes, resulting in the catalytic "OFF" state. Moreover, the nonequilibrium nanoreactors could be reinitiated several cycles as long as fuel was supplied. This feedback-induced temporal control of catalytic activity in polymersome nanoreactors provides a platform for functional nonequilibrium systems as well as for artificial organelles with precisely controlled adaptivity.

Tnspired by biology, chemists have created a plethora of synthetic adaptive or life-like materials with temporal control over structure and function by employing chemical and enzymatic reaction networks. These materials are endowed with unique features because of their out-of-equilibrium state, compared to conventional equilibrium systems that demonstrate thermodynamic stability. ${ }^{1}$ Although nonequilibrium systems have been well studied, these are mostly related to structural changes, whereas systems with biomimetic selfadaptive function are less common. In this regard, fuel-driven functional operations under temporal control are thought to play a key role in bridging man-made materials and biology in terms of natural organization and function. For example, DNAbased systems have paved the way for the development of autonomous molecular walkers and nanomotors mediated by fuel and catalytic units. ${ }^{2}$

Polymeric vesicles, or polymersomes, are versatile compartments that have been developed for a range of applications, including nanoreactors. ${ }^{3}$ To regulate the transport of substrate across the polymer membrane barrier, stimuli-responsive polymersomes that can sense changes in the environment have been designed and constructed. ${ }^{4}$

The bell-shaped $\mathrm{pH}$-activity curve of urease coupled with its ability to produce base has provided a platform to attain temporal control over $\mathrm{pH}$ feedback systems. ${ }^{5}$ Recently, we have shown the construction of a self-regulated and timeprogrammed "breathing" microgel that uses chemical fuels to keep the system in an out-of-equilibrium state. ${ }^{6}$ Here we report an artificial organelle with precisely controlled adaptive dynamic behavior and enzymatic activity. The envisioned feedback-induced temporal control of the polymersome nanoreactors is depicted in Figure 1a. Urease, which controls

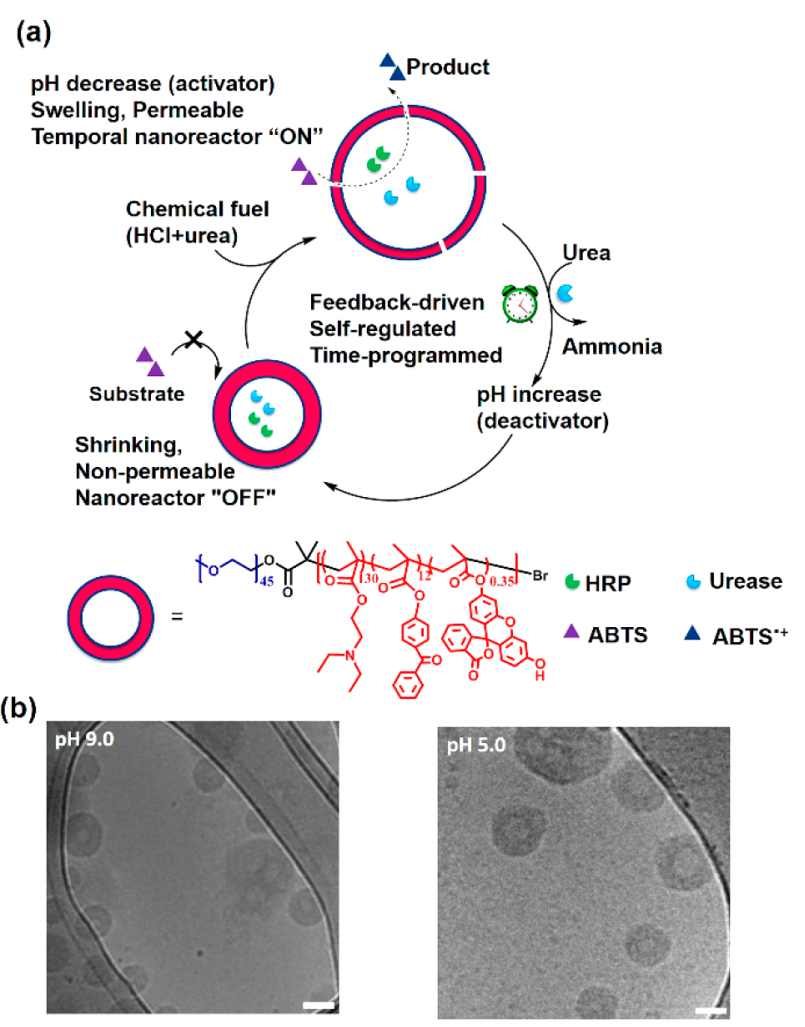

Figure 1. (a) Schematic overview of feedback-induced temporal control of polymersome nanoreactors. (b) Cryo-TEM images of polymersomes at $\mathrm{pH} 9.0$ (left) and $\mathrm{pH} 5.0$ (right). All scale bars are $100 \mathrm{~nm}$.

the $\mathrm{pH}$ change, and horseradish peroxidase (HRP), which acts as model enzyme, are encapsulated in the polymersomes. First, polymersome nanoreactors are dispersed in a high $\mathrm{pH}$ buffer. This causes the polymersomes to shrink due to deprotonation of the $\mathrm{pH}$-sensitive polymers. In this situation, the nanoreactors are nonpermeable and substrates cannot pass the polymer membranes, giving rise to a nanoreactor "OFF" state (left). Addition of chemical fuel $(\mathrm{HCl}$ and urea) results in a fast $\mathrm{pH}$ decrease, thereby increasing the size of the polymersomes. The

Received: March 7, 2018

Published: April 4, 2018 
swelling leads to increased polymer membrane permeability, turning the nanoreactor in the "ON" state as the substrate is able to penetrate into the polymersomes (above). Over time, a gradual increase in $\mathrm{pH}$ occurs through the conversion of urea into ammonia. Thus, polymersomes return to their initial shrunken state and the enzyme catalysis automatically changes to "OFF" again. A continuous addition of chemical fuels to the system allows the "ON" and "OFF" process to be reversible.

To realize this aim, amphiphilic copolymers consisting of poly(ethylene glycol) (PEG) and pH-responsive poly[2(diethylamino) ethyl methacrylate (PDEAEMA) were synthesized. Poly[2-hydroxy-4-(methacryloyloxy) benzophenone] (PBMA) was used as a photo-cross-linkable block, and a fluorescein group was introduced as a fluorescence read-out platform (Supporting Information, Scheme S1, Figure S1 and Figure S2). Block copolymer $\mathrm{mPEG}_{45}-b-\mathrm{P}\left(\mathrm{DEAEMA}_{130^{-}} \mathrm{co}\right.$ $\left.\mathrm{BMA}_{12}-\mathrm{co}-\mathrm{FMA}_{0.35}\right)$ was self-assembled into $\mathrm{pH}$-responsive polymersomes by the nanoprecipitation method and subsequently cross-linked. ${ }^{7}$ During the formation of polymersomes, HRP and urease were coencapsulated. Urease was labeled with Rhodamine-B ( $\mathrm{RhB}$ ) before encapsulation, which did not affect the high activity of the enzyme (Figure S3). From HRP's characteristic Soret band with a maximum at $403 \mathrm{~nm}^{4 \mathrm{~g}}$ and RhB's absorbance at $550 \mathrm{~nm}$, the urease and HRP loading content was determined to be $25 \%$ and $14 \%$, respectively, after disassembly of the polymersomes (Supporting Information, Figure S4). Asymmetric flow field-flow fractionation (AF4, settings in Table S1), was used to determine particle morphology. The ratio between the radius of gyration $\left(R_{\mathrm{g}}\right)$ and the hydrodynamic radius $\left(R_{\mathrm{h}}\right)$ was close to 1 , indicative of vesicle formation (Figure S5). ${ }^{8}$ Transmission electron microscopy (TEM) and cryogenic TEM images of the polymersomes confirmed a vesicular structure at both basic and acidic conditions (Figure $1 \mathrm{~b}$, and Figure S6). Dynamic light scattering (DLS) measurements revealed an $R_{\mathrm{h}}$ increase from 102 to $183 \mathrm{~nm}$ when the $\mathrm{pH}$ was decreased from 9 to 5 (Figure S7). The average $R_{\mathrm{h}}$ was plotted against solution $\mathrm{pH}$ and reversibility upon $\mathrm{pH}$ variation was observed during multiple cycles of swelling and shrinking (Figure S8, and Figure S9).

The feedback-driven $\mathrm{pH}$ regulation of the polymersomes was first investigated. The polymersome solution was brought to pH 9.0 (N-cyclohexyl-2-aminoethanesulfonic acid (CHES) buffer, $10 \mathrm{mM}$ ), under which conditions urease is inactive. Upon addition of a concentrated solution of urea and $\mathrm{HCl}$, the $\mathrm{pH}$ of the polymersome solution was instantaneously brought down to 5.0, at which point urease was activated. This was reflected by a gradual increase in $\mathrm{pH}$ due to the conversion of urea into ammonia. The final $\mathrm{pH}$ value leveled off at approximately the original level, as the urease activity was self-diminished at high $\mathrm{pH}$. By changing [urea] from 2 to 10 $\mathrm{mM}$ (urease level constantly maintained at $30 \mathrm{U} / \mathrm{mL}$ ), the $\mathrm{pH}$ recovery time was decreased (Figure 2a). More interestingly, the out-of-equilibrium situation was reinitiated by the repeated addition of chemical fuel over five cycles (Figure S10). The dynamic $\mathrm{pH}$ regulation behavior was also validated using fluorescence spectroscopy, as fluorescein incorporated in the polymersome membranes could change its fluorescence intensity concurrently with the change in $\mathrm{pH}$ (Figure $2 \mathrm{~b}$, Figures S11 and S12).

Next, polymersome size evolution upon addition of the acidic urea solution was investigated by DLS. As expected, the polymersomes first quickly increased to a maximum size of $R_{\mathrm{h}}=$ $182 \mathrm{~nm}$, followed by an autonomous size recovery, until they (a)

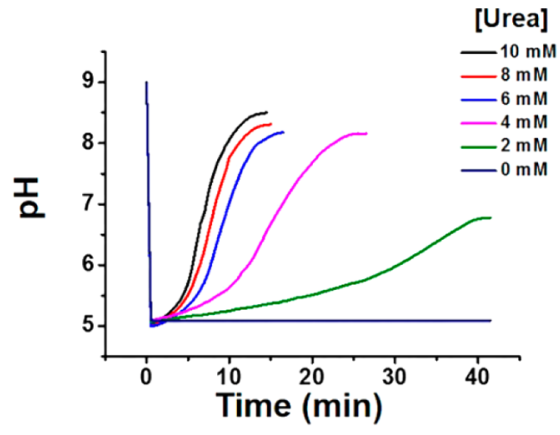

(b)

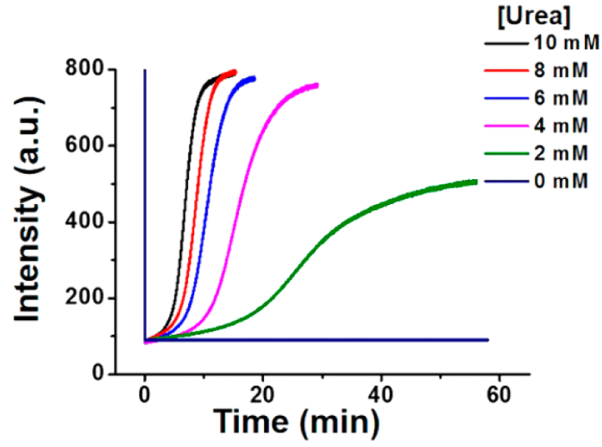

Figure 2. Plots of the (a) $\mathrm{pH}$ and (b) fluorescence intensity switch of the polymersome nanoreactor solution against time in a nonequilibrium cycle for different initial urea concentrations. The concentration of urease in the polymersomes is $30 \mathrm{U} / \mathrm{mL}$.

finally reached the starting situation $\left(R_{\mathrm{h}}=101 \mathrm{~nm}\right.$ ) (Figure S13). The spontaneous expansion and contraction of these polymersomes endows them with a "breathing" feature. In contrast to other reported "breathing" vesicles with changeable sizes, ${ }^{9}$ our system follows a self-regulated mechanism. In addition, this polymersome size evolution process was perfectly modulated by varying concentrations of the substrate (Figure 3). Thus, an increase in substrate gives rise to a decrease in the swelling lifetimes and an acceleration of the rate of polymersome "breathing". Figure $3 \mathrm{c}$ shows average induction periods within five cycles. The expansion-contraction process was reinitiated with controllable lifetimes by urea supply over five cycles, and the $\mathrm{pH}$ and size modulations followed almost a similar trend during each cycle (Figure 2d).

As the self-regulated "breathing" behavior of the polymersomes is correlated to a temporal change in membrane permeability, these compartments are attractive as adaptive nanoreactors with automatically modulated catalysis. First, the effect of $\mathrm{pH}$ on the activity of free and encapsulated HRP was investigated, using an ABTS assay. As shown in Figure S14, $\mathrm{HRP}$ displays $\mathrm{pH}$-dependent activity, with a slight increase from $\mathrm{pH} 5.0$ to 6.0, and a gradual decrease from $\mathrm{pH} 6.0$ to 9.0. When HRP was encapsulated in the responsive polymersomes, nearly the same activity profile was observed in the $\mathrm{pH}$ range from 5.0 to 6.0. However, the HRP activity significantly dropped below $5 \%$ when the $\mathrm{pH}$ was increased above 6.5 , while the corresponding free HRP activity remained above $40 \%$ (Figure S15). This enzyme activity difference between free HRP and encapsulated HRP can be ascribed to the $\mathrm{pH}$ triggered polymersome permeability change. At high $\mathrm{pH}$ value, the PDEAEMA block is deprotonated, therefore the polymersome membranes are fully hydrophobic, and substrates cannot diffuse into the polymersome lumen. When the $\mathrm{pH}$ is below the $\mathrm{p} K_{\mathrm{a}}$ (around 7.0) of PDEAEMA, the polymersome membranes 

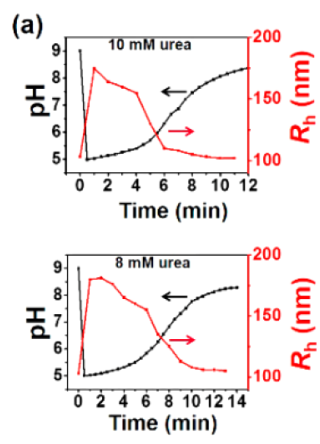

(b)

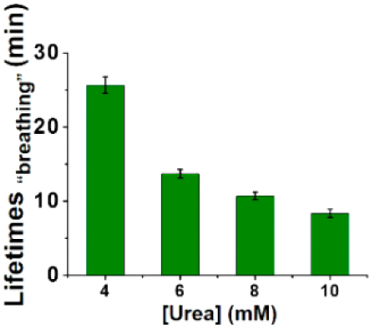

(c)
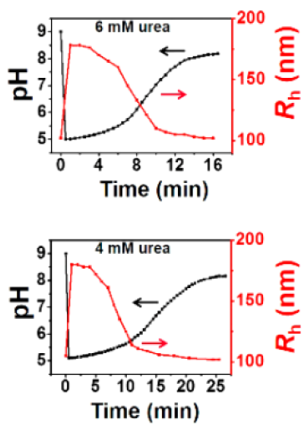

(d)

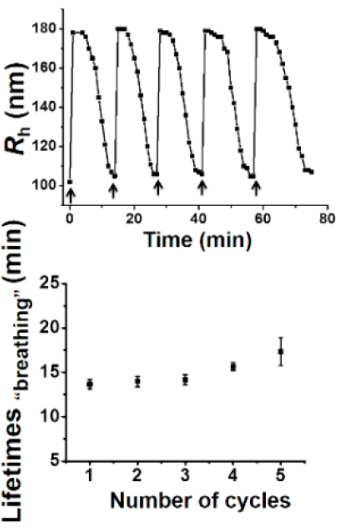

Figure 3. (a) Influence of the urea concentration on the size changes of the polymersome nanoreactor solution. Urea concentrations from top to bottom: 10, 8, 6, and $4 \mathrm{mM}$. (b) Average transient periods of polymersome "breathing" as a function of the urea concentration. (c) Reversible $R_{\mathrm{h}}$ changes of the polymersomes in time following repeated additions of chemical fuel (6 mM urea). (d) Average transient periods of "breathing" within five cycles (6 $\mathrm{mM}$ urea in all cases). Concentrations of urease in the polymersomes are $30 \mathrm{U} / \mathrm{mL}$.

change to a swollen and permeable state, which allows for the catalytic reaction to occur.

Next, we sought to develop dissipative polymersome nanoreactors with out-of-equilibrium catalytic behavior. For this purpose, polymersomes were loaded with both HRP and urease. Initially, the samples were incubated in $\mathrm{pH} 9.0$ buffer, and no absorbance at $416 \mathrm{~nm}$ was observed, suggesting the catalytic "OFF" state due to the nonpermeable polymersome membrane. When acidic urea was applied to the system, the HRP enzymatic reaction first became activated and subsequently turned dormant (Figure 4a). This self-controlled catalysis behavior of the nanoreactors was caused by the temporally programmed "breathing" feature and permeability modulation of the polymersome membranes.

As the concentration of urea determines the lifetime of the membrane shrinking and swelling process, we reasoned that we could tune the yield of the ABTS oxidation process. Samples with different urea concentration $(4,6,8$, and $10 \mathrm{mM}$ ) underwent a gradual increase in the absorbance at $416 \mathrm{~nm}$ after addition of chemical fuel, which leveled off to a constant value. The higher the concentration of urea, the faster the catalysis reached its end point. Most interestingly, an approximately linear relationship between the concentration of added urea and the nanoreactor "ON" lifetimes as well as the final yield was observed (Figure 4b).

As this fuel-driven temporal nanoreactor is in principle a switchable process, the self-adaptive cycle was refueled by the consecutive introduction of urea. In a control experiment where the free HRP-based enzymatic reaction was performed, the absorbance over time $(60 \mathrm{~min})$ at $416 \mathrm{~nm}$ was linear, which confirms that the amount of substrate is not limiting in the (a)

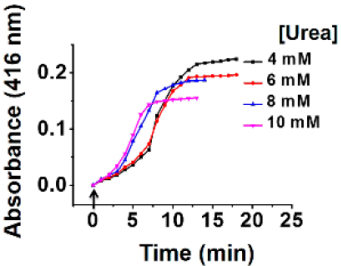

(c)

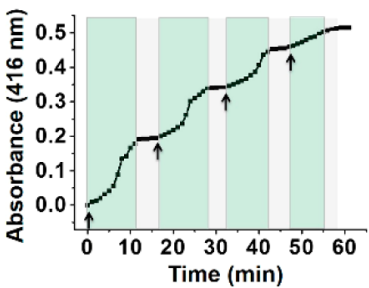

(b)

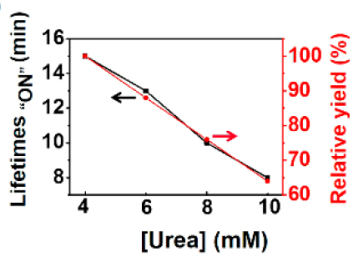

Nanoreactor "ON"

Nanoreactor "OFF"

$\uparrow:$ Addition of chemical fuel

Figure 4. (a) UV absorbance at $416 \mathrm{~nm}$ of the oxidation of ABTS by nanoreactors upon the addition of different concentrations of urea. (b) Lifetimes (black line) of the nanoreactor "ON" state and relative yield (red line) as a function of urea concentration. (c) Reversible nanoreactor "ON-OFF" modulation in time following repeated additions of $6.0 \mathrm{mM}$ urea. Experimental conditions: Urease, $30 \mathrm{U} / \mathrm{mL}$; $\mathrm{HRP}, 10 \mathrm{U} / \mathrm{mL}$; ABTS, $8 \mathrm{mM} ; \mathrm{H}_{2} \mathrm{O}_{2}, 5 \mathrm{mM}$.

study (Figure S16). Identical to polymersome swelling and shrinking behavior, three consecutive nanoreactor "OFF-ONOFF" cycles could be achieved, supporting the above mechanism of feedback-driven membrane permeability modulation (Figure 4c). We need to note, however, that the efficiency of the self-regulated catalytic reaction decreased after three cycles, whereas the reversible polymersome expansion and contraction could be performed for at least six cycles. The reversible $\mathrm{pH}$ changes of the enzyme-filled polymersomes in the presence of ABTS clearly shows that the product of the HRP reaction does not have an effect on the lifetime of the polymersome nanoreactors (Figure S17). So, one possible reason is that the activity of HRP is affected by continuous $\mathrm{pH}$ regulation and accumulation of waste (ammonia and $\mathrm{CO}_{2}$ ).

In summary, we have presented a self-adaptive polymersome nanoreactor that drives a catalytic reaction out-of-equilibrium by temporal control of the permeability of the polymersome membranes. This is achieved by implementing the urease-based $\mathrm{pH}$ feedback system in HRP-filled polymersomes, which induces "breathing" behavior in the nanoreactor. Compared to the previously reported classical nanoreactors that operate in a thermodynamically controlled one-way transition, the nonequilibrium nanoreactor functions with an "ON-OFF" switch in a biocatalytically controlled fashion. Hence the catalytically active period of HRP in the nanoreactors is governed by the amount of substrate present to steer the urease cycle, and the reversible nature is demonstrated for several cycles by refueling the system. The principle of feedback-induced temporal control of nanoreactors is an important addition to the area of nonequilibrium systems. We anticipate that the basic design rules in this work will promote engineering of artificial organelles with adaptive features.

\section{ASSOCIATED CONTENT}

\section{Supporting Information}

The Supporting Information is available free of charge on the ACS Publications website at DOI: $10.1021 /$ jacs.8b02387.

Synthesis, methods, and supporting data (PDF) 


\section{AUTHOR INFORMATION}

Corresponding Author

*j.c.m.v.hest@tue.nl

ORCID $\odot$

Jan C. M. van Hest: 0000-0001-7973-2404

Notes

The authors declare no competing financial interest.

\section{ACKNOWLEDGMENTS}

The authors acknowledge the Dutch Science Foundation (VICI grant), the ERC Advanced grant Artisym 694120, the Dutch Ministry of Education, Culture and Science (Gravitation program 024.001.035) and the European Union's Horizon 2020 research and innovation programme Marie SklodowskaCurie Innovative Training Networks Nanomed, (No. 676137) for funding. We also thank Imke Pijpers and Alex Mason for help with Cryo-TEM measurements.

\section{REFERENCES}

(1) (a) Heinen, L.; Walther, A. Soft Matter 2015, 11, 7857. (b) Merindol, R.; Walther, A. Chem. Soc. Rev. 2017, 46, 5588. (c) della Sala, F.; Neri, S.; Maiti, S.; Chen, J. L.; Prins, L. J. Curr. Opin. Biotechnol. 2017, 46, 27. (d) van Roekel, H. W.; Rosier, B. J.; Meijer, L. H.; Hilbers, P. A.; Markvoort, A. J.; Huck, W. T.; de Greef, T. F. Chem. Soc. Rev. 2015, 44, 7465. (e) Boekhoven, J.; Hendriksen, W. E.; Koper, G. J.; Eelkema, R.; van Esch, J. H. Science 2015, 349, 1075. (f) Van Ravensteijn, B. G.; Hendriksen, W. E.; Eelkema, R.; Van Esch, J. H.; Kegel, W. K. J. Am. Chem. Soc. 2017, 139, 9763. (g) Debnath, S.; Roy, S.; Ulijn, R. V. J. Am. Chem. Soc. 2013, 135, 16789. (h) Tena-Solsona, M.; Rieß, B.; Grötsch, R. K.; Löhrer, F. C.; Wanzke, C.; Käsdorf, B.; Bausch, A. R.; Müller-Buschbaum, P.; Lieleg, O.; Boekhoven, J. Nat. Commun. 2017, 8, 15895. (i) Dhiman, S.; Jain, A.; Kumar, M.; George, S. J. J. Am. Chem. Soc. 2017, 139, 16568. (j) Jalani, K.; Dhiman, S.; Jain, A.; George, S. J. Chem. Sci. 2017, 8, 6030. (k) Hao, X.; Sang, W.; Hu, J.; Yan, Q. ACS Macro Lett. 2017, 6, 1151. (1) Maiti, S.; Fortunati, I.; Ferrante, C.; Scrimin, P.; Prins, L. J. Nat. Chem. 2016, 8, 725.

(2) (a) Yin, P.; Yan, H.; Daniell, X. G.; Turberfield, A. J.; Reif, J. H. Angew. Chem., Int. Ed. 2004, 43, 4906. (b) Lund, K.; Manzo, A. J.; Dabby, N.; Michelotti, N.; Johnson-Buck, A.; Nangreave, J.; Taylor, S.; Pei, R.; Stojanovic, M. N.; Walter, N. G.; et al. Nature 2010, 465, 206. (c) Cha, T.-G.; Pan, J.; Chen, H.; Salgado, J.; Li, X.; Mao, C.; Choi, J. H. Nat. Nanotechnol. 2014, 9, 39. (d) Wickham, S. F.; Endo, M.; Katsuda, Y.; Hidaka, K.; Bath, J.; Sugiyama, H.; Turberfield, A. J. Nat. Nanotechnol. 2011, 6, 166. (e) Yehl, K.; Mugler, A.; Vivek, S.; Liu, Y.; Zhang, Y.; Fan, M.; Weeks, E. R.; Salaita, K. Nat. Nanotechnol. 2016, 11,184 .

(3) (a) Che, H.; van Hest, J. C. J. Mater. Chem. B 2016, 4, 4632. (b) Palivan, C. G.; Goers, R.; Najer, A.; Zhang, X.; Car, A.; Meier, W. Chem. Soc. Rev. 2016, 45, 377. (c) Tanner, P.; Baumann, P.; Enea, R; Onaca, O.; Palivan, C.; Meier, W. Acc. Chem. Res. 2011, 44, 1039. (d) Schoonen, L.; van Hest, J. Adv. Mater. 2016, 28, 1109. (e) Buddingh', B. C.; van Hest, J. C. Acc. Chem. Res. 2017, 50, 769. (f) Marguet, M.; Bonduelle, C.; Lecommandoux, S. Chem. Soc. Rev. 2013, 42, 512

(4) (a) Hu, J.; Zhang, G.; Liu, S. Chem. Soc. Rev. 2012, 41, 5933. (b) Feng, A.; Yuan, J. Macromol. Rapid Commun. 2014, 35, 767. (c) Kim, K. T.; Meeuwissen, S. A.; Nolte, R. J.; van Hest, J. C. Nanoscale 2010, 2, 844. (d) Peters, R. J.; Louzao, I.; van Hest, J. C. Chem. Sci. 2012, 3, 335. (e) Hu, X.; Zhang, Y.; Xie, Z.; Jing, X.; Bellotti, A.; Gu, Z. Biomacromolecules 2017, 18, 649. (f) Le Meins, J.F.; Sandre, O.; Lecommandoux, S. Eur. Phys. J. E: Soft Matter Biol. Phys. 2011, 34, 14. (g) Spulber, M.; Najer, A.; Winkelbach, K.; Glaied, O.; Waser, M.; Pieles, U.; Meier, W.; Bruns, N. J. Am. Chem. Soc. 2013, 135, 9204. (h) Edlinger, C.; Einfalt, T.; Spulber, M.; Car, A.; Meier, W.; Palivan, C. G. Nano Lett. 2017, 17, 5790. (i) Einfalt, T.; Goers, R.; Dinu, I. A.; Najer, A.; Spulber, M.; Onaca-Fischer, O.; Palivan, C. G.
Nano Lett. 2015, 15, 7596. (j) Kim, K. T.; Cornelissen, J. J.; Nolte, R. J.; van Hest, J. Adv. Mater. 2009, 21, 2787. (k) Yan, Q.; Wang, J.; Yin, Y.; Yuan, J. Angew. Chem., Int. Ed. 2013, 52, 5070.

(5) (a) Hu, G.; Pojman, J. A.; Scott, S. K.; Wrobel, M. M.; Taylor, A. F. J. Phys. Chem. B 2010, 114, 14059. (b) Russell, A. J.; Erbeldinger, M.; DeFrank, J. J.; Kaar, J.; Drevon, G. Biotechnol. Bioeng. 2002, 77, 352. (c) Heuser, T.; Weyandt, E.; Walther, A. Angew. Chem., Int. Ed. 2015, 54, 13258. (d) Heinen, L.; Walther, A. Chem. Sci. 2017, 8, 4100. (e) Heuser, T.; Merindol, R.; Loescher, S.; Klaus, A.; Walther, A. Adv. Mater. 2017, 29, 1606842. (f) Okamoto, Y.; Ward, T. R. Angew. Chem., Int. Ed. 2017, 56, 10156. (g) Jee, E.; Bánsági, T.; Taylor, A. F.; Pojman, J. A. Angew. Chem., Int. Ed. 2016, 55, 2127.

(6) Che, H.; Buddingh, B. C.; van Hest, J. C. M. Angew. Chem., Int. Ed. 2017, 56, 12581.

(7) (a) Gaitzsch, J.; Appelhans, D.; Wang, L.; Battaglia, G.; Voit, B. Angew. Chem., Int. Ed. 2012, 51, 4448. (b) Iyisan, B.; Kluge, J. r.; Formanek, P.; Voit, B.; Appelhans, D. Chem. Mater. 2016, 28, 1513. (c) Gaitzsch, J.; Appelhans, D.; Gräfe, D.; Schwille, P.; Voit, B. Chem. Commun. 2011, 47, 3466.

(8) (a) Brewer, A. K.; Striegel, A. M. Analyst 2011, 136, 515. (b) Abdelmohsen, L. K. E. A.; Williams, D. S.; Pille, J.; Ozel, S. G.; Rikken, R. S. M.; Wilson, D. A.; van Hest, J. C. M. J. Am. Chem. Soc. 2016, 138, 9353.

(9) (a) Yu, S.; Azzam, T.; Rouiller, I.; Eisenberg, A. J. Am. Chem. Soc. 2009, 131, 10557. (b) Yan, Q.; Zhou, R.; Fu, C.; Zhang, H.; Yin, Y.; Yuan, J. Angew. Chem. 2011, 123, 5025. 